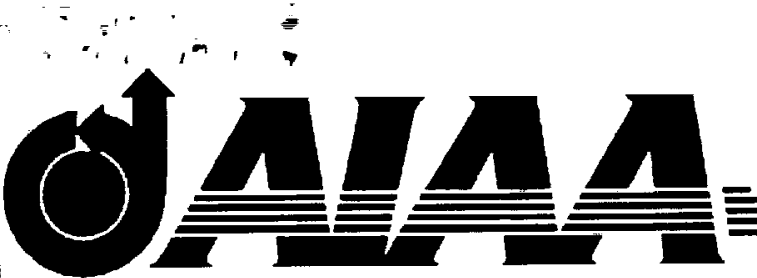

AIAA 2001-3413

\title{
Achieving Space Shuttle ATO Using the Five-Segment Booster (FSB)
}

Donald R. Sauvageau

Thiokol Propulsion

Brigham City, UT

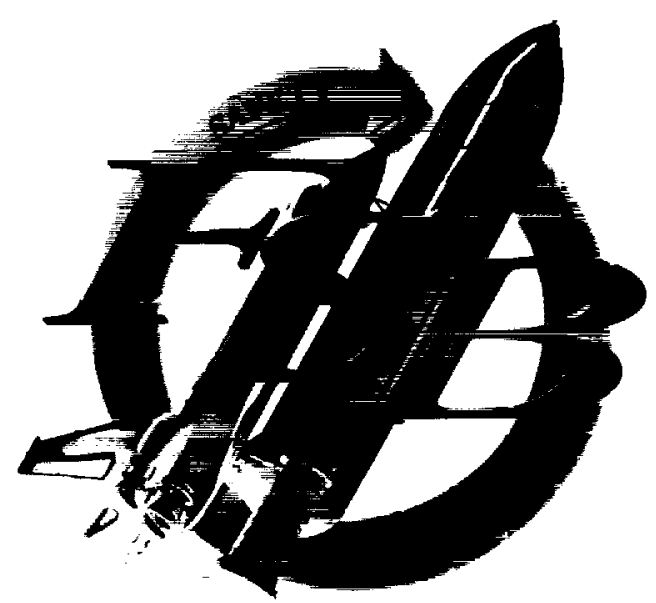

FIVE SEGMENT BOOSTER

\section{AIAA Joint Propulsion Conference \\ July 9-11, 2001 \\ Salt Lake City, Utah}




\title{
ACHIEVING SPACE SHUTTLE ATO USING THE FIVE-SEGMENT BOOSTER (FSB)
}

\author{
Donald R. Sauvageau \\ Thiokol Propulsion \\ Brigham City, Utah
}

As part of the continuing effort to identify approaches to improve the safety and reliability of the Space Shuttle system, a Five-Segment Booster (FSB) design was conceptualized as a replacement for the current Space Shuttle boosters. The FSB offers a simple, unique approach to improve astronaut safety and increase performance margin.

To determine the feasibility of the FSB, a Phase A study effort was sponsored by NASA and directed by the Marshall Space Flight Center (MSFC). This study was initiated in March of 1999 and completed in December of 2000. The basic objective of this study was to assess the feasibility of the FSB design concept and also estimate the cost and scope of a full-scale development program for the FSB. In order to ensure an effective and thorough evaluation of the FSB concept, four team members were put on contract to support various areas of importance in assessing the overall feasibility of the design approach.

Thiokol was responsible for performing all of the motor design and overall FSB integration effort. Boeing North American conducted all of the systems integration studies, which included performance assessments and load evaluations. United Space Alliance (USA), in conjunction with United Space Boosters Incorporated (USBI) and BD Systems, evaluated all of the booster element design aspects as well as the Kennedy Space Center (KSC) site implications. Lockheed Martin Space Systems Company, Michoud Operations (LMSSC) was responsible for determining impacts to the external tank (ET) design.
When the Phase A study was initiated, the basic objective of the FSB design concept was to eliminate the return to launch site (RTLS) abort mode by providing transatlantic landing (TAL) abort capability from the pad. In conjunction with achieving the basic performance objective of eliminating RTLS, we also imposed the requirement of minimizing the impacts on other Shuttle elements, which entailed ensuring that the current external tank (ET) and pad interface control documents (ICD) were maintained as well as ensuring that there were no increases in the design driving loads or environments on the orbiter. Additionally, we were to minimize the changes to the current Shuttle reusable solid rocket booster (RSRB) hardware, and infrastructure, thus maximizing the utilization of the flight-proven design materials and processes that are currently being successfully used on the Space Shuttle system. The basic conceptual design approach taken for the FSB is shown in Figure 1.

Essentially what has been done is add a center segment. As a result of the incorporation of an additional center segment, a new nozzle had to be designed to accommodate the increased mass flow rate associated with the added propellant. To maintain the existing interface with the ET, the forward attach provisions had to be changed from the current forward skirt to the external surface on the booster forward segment. Since the forward skirt no longer needs to take up the forward thrust loads, a new forward skirt was designed that was a much simpler configuration. As a result of adding a center segment, the inert weight of the boosters increased. Therefore, to ensure the same attrition 


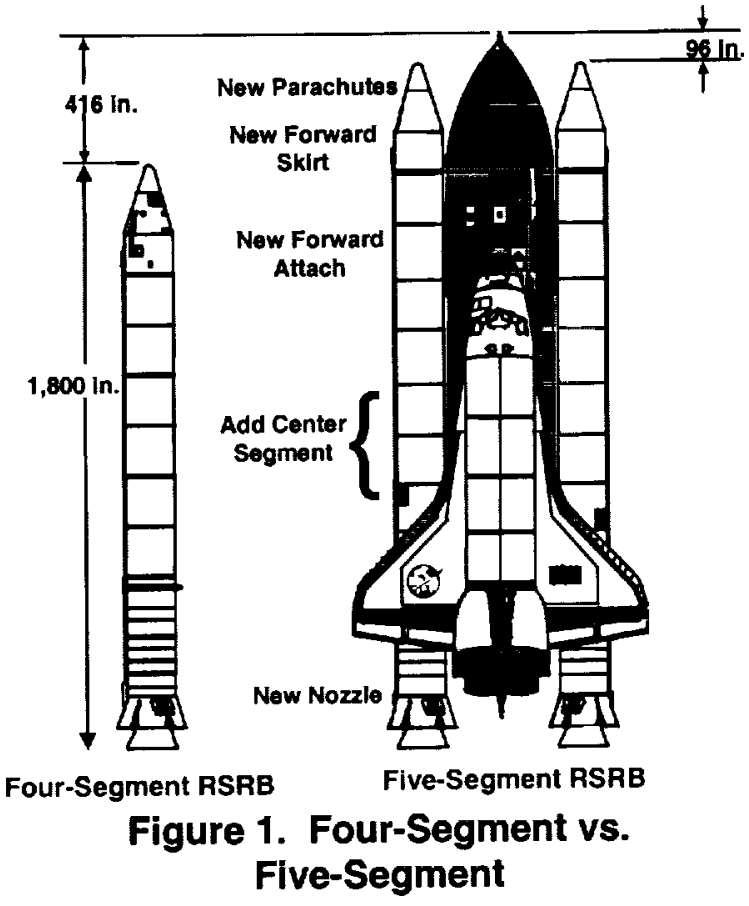

rate was achieved, new larger-diameter parachutes were designed to ensure that the water impact velocity was the same as it is in today's boosters.

Since new metal cylinders would need to be fabricated for the forward segment to accommodate the interface to the ET, there was flexibility available to make the forward segment as long as would be needed to satisfy the overall program objectives. As such, a process study was conducted to determine what maximum-length forward segment could be processed through the Thiokol and KSC infrastructures. That study determined that the forward segment could be increased 26 inches over what the current forward segment design provides. This allowed additional propellant to be included in the FSB concept, thus increasing the overall capability of the booster. Since the forward segment was increased 26 inches, in order to maintain the same total booster length, the new forward skirt was shortened the same 26 inches.

In order to maintain the pressure capability of the case with the added segment, a lower-burn- rate propellant had to be included in the design. This propellant is the same formulation as that used in the existing Shuttle booster. The lower burn rate is achieved by a slight reduction in the iron oxide burn rate catalyst used in the basic formulation of the propellant. The nozzle throat diameter was also increased 5.8 inches to accommodate the increased mass flow rate from the added center segment. The increased throat diameter in conjunction with the reduced burn rate allowed us to maintain the same maximum expected operating pressure (MEOP) that the case hardware was originally designed for. The nozzle exit cone was increased in length by eight inches and diameter by three inches, corresponding with the changes that had been previously qualified on an earlier flight support motor supporting earlier Shuttle upgrade activities.

Since these increased dimensions were evaluated as part of the Shuttle upgrade efforts associated with supporting the increased pay load necessary for Space Station Alpha missions, these dimensions were evaluated by the systems integration community and found to be acceptable from both processing and clearance perspectives. Thus, we were reasonably confident that this would be an acceptable design consideration for the FSB. This allowed us to compensate for some of the reduced expansion ratio associated with the increase in throat diameter.

With the added inert weight associated with the center segment, the water impact forces will be somewhat greater than experienced by the current Shuttle RSRB. Therefore, with the FSB, all four stiffeners on the aft segment will be installed at $\mathrm{KSC}$ as opposed to the three that are currently installed. This will provide additional cavity collapse load capability for the aft segment to accommodate the higher splashdown loads. We are 
also using standard weight stiffener segments on the aft segment to accommodate the higher buckling loads associated with the heavier FSB.

To provide the necessary thrust history, we needed to modify some of the propellant grain geometry. The biggest change was increasing the number of fins in the forward segment from the current 11 to 13 . We also changed the inhibitor heights to tailor the thrust profile to match necessary system performance constraints. One of the areas of concern with the higher mass flow rate and increased length-to-diameter ratio of the motor is the potential for erosive burning in the bore of the motor during the first second of motor operation. To help minimize this impact, the leading edges of all center segments and the aft segment were chamfered to provide a smoother aerodynamic transition between segments. With the change in inhibitor heights and grain geometry, the propellant burn-back pattern also changed, necessitating a change in the insulation design to accommodate the increased exposure times in many areas of the motor. However, both the insulation and the nozzle materials are exactly the same as the current Reusable Solid Rocket
Motor's (RSRM), and thus their performance in the modified environment of the FSB will be well understood and the risk associated with the design changes will be minimal. Most of these design changes are graphically depicted in Figures 1 and 2. The change to the 13-fin grain geometry is shown in Figure 3.

The simplified forward skirt design, which consists of stringers with a skin welded over the top, is also shown in Figure 3. One of the design features of this simplified skirt design is the ability to easily replace skin panels if they are damaged as a result of splashdown loads. This skirt is also significantly lighter weight and lower cost than the existing skirt, which is by necessity more complex to facilitate the distribution of the thrust loads for the booster. Since the thrust loads for the booster on the FSB are going to be taken out on the surface of the forward segment of the motor, the design modifications necessary to accommodate that are also shown in Figure 3. The basic approach is to have circumferential stiffeners integrally machined into the case wall cylinder and a thrust post attached to the stiffener rings to transfer the loads from the booster to the ET.
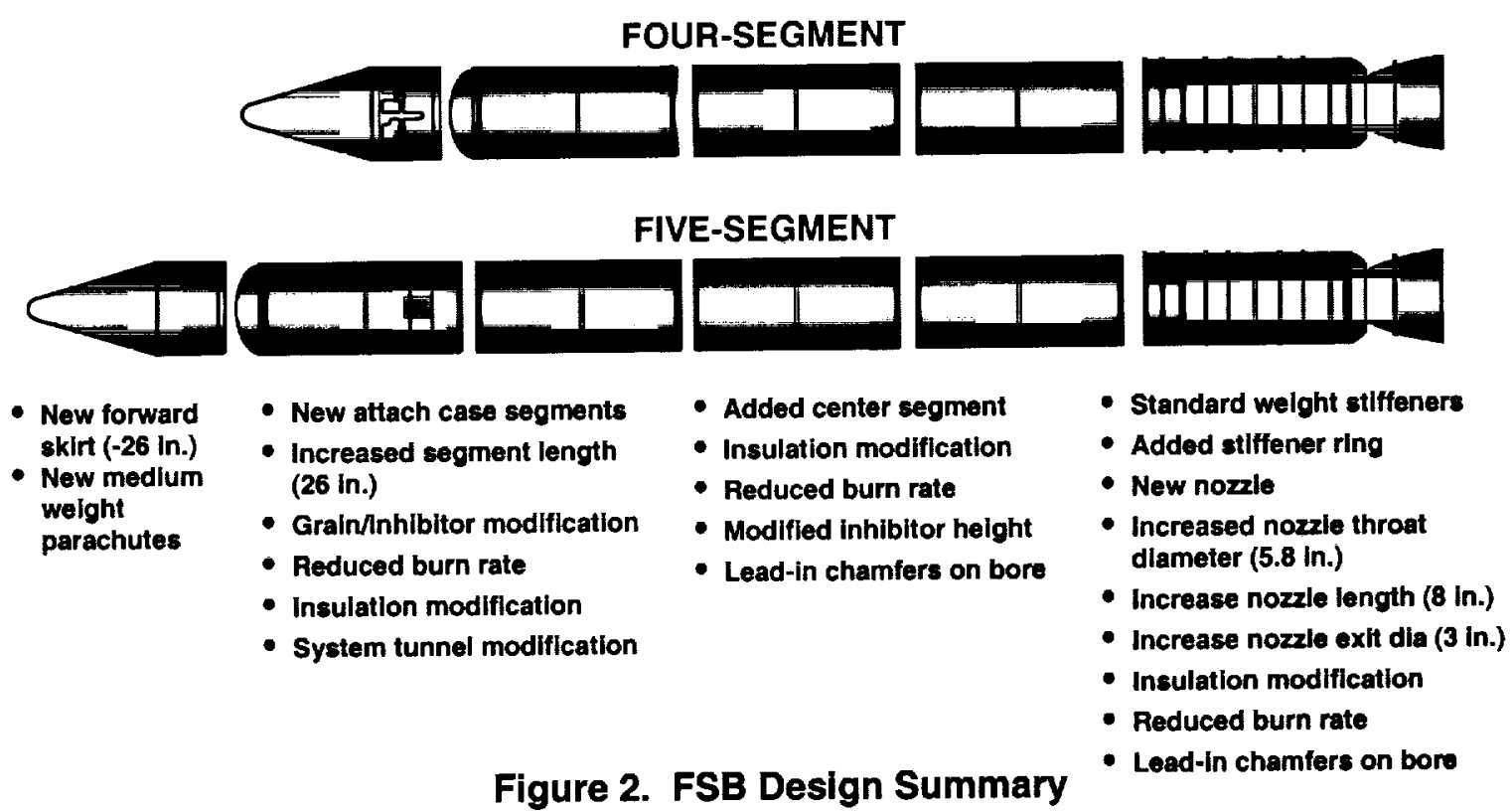


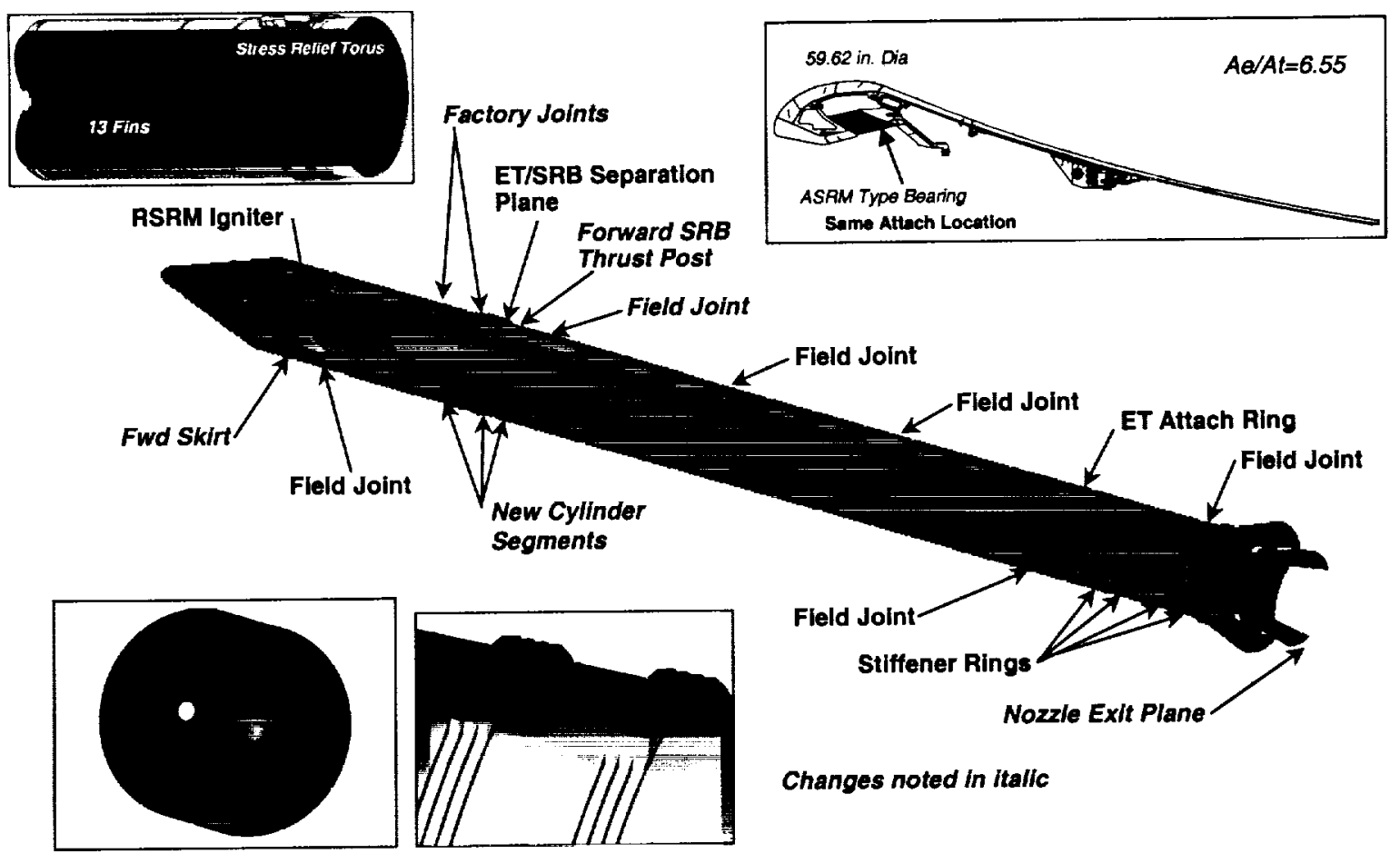

Figure 3. FSB RSRM Enhancements

Because of the substantial increase in throat diameter, a totally new nozzle will need to be designed. The new nozzle will utilize the same materials that are currently being flown on the RSRM, but will take advantage of many of the lessons learned from the current RSRM program as well as those design improvements identified as part of the Advanced Solid Rocket Motor (ASRM) program. This historical perspective will enable changes to design features that will increase the overall reliability of the FSB nozzle relative to the current RSRM nozzle. Not because the current nozzle is poorly designed, but with the significant knowledge gained from recovered hardware from flight as well as the multiple test firings that have occurred, the knowledge and understanding of how the RSRM nozzle performs is greater than any other nozzle design in existence. As such, that insight provides opportunities to enhance the overall reliability and robustness of the new FSB nozzle.
The basic performance characteristics of the FSB are shown in Figure 4. To provide a relative

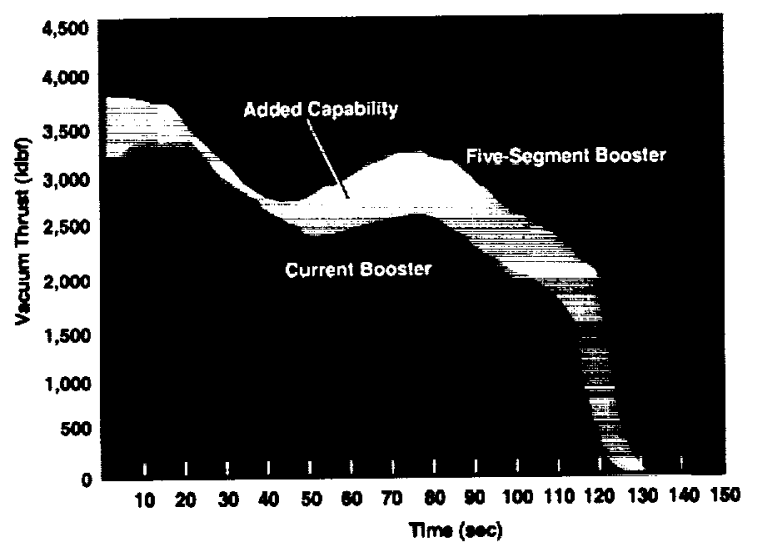

Booster Performance

$\begin{array}{lrr} & 5-S e g m e n t & 4-S e g m e n t \\ \text { Total Impulse (Mlbf-sec) } & 368.0 & 296.3 \\ \text { Max Thrust (lbf) } & 3,799,000 & 3,331,400 \\ \text { Average Thrust (lbf) } & 2,843,500 & 2,395,000 \\ \text { Average Pressure } & 639 & 625 \\ \text { MEOP (psi) } & 1016 & 1016 \\ \text { Ispv (sec) } & 264.7 & 268.0 \\ \text { Burn Tlme (sec) } & 129.6 & 123.5 \\ \text { Burn Rate (In/sec) } & 0.343 & 0.368 \\ \text { Expansion Ratlo } & 6.55 & 7.72 \\ \text { Throal Dlamoter (in.) } & 59.62 & 53.86 \\ \text { Initial ThrustWeight } & 1.57 & 1.52\end{array}$

Figure 4. FSB Design Performance 
reference and point of comparison, the same performance characteristics for the current foursegment RSRM are also included. To ensure that the existing case hardware could still be used on the FSB, note that the MEOP was constrained to be the same. To accommodate the increased mass flow from the added segment, the throat diameter was increased from 53.8 inches to 59.6 inches, which resulted in a decrease in expansion ratio from 7.72 to 6.55 . This also resulted in a decrease in specific impulse from 268 to 264.7 seconds. Because of the increased throat diameter and mass flow rate, the thrust level increased about 500,000 lbf. The burn time increased from 123.5 seconds to 129.6 seconds for the FSB. One of the key system parameters that drove the grain design for the FSB was the ability for the nozzle to clear the hold-down posts on the mobile launch platform (MLP). In order to ensure that we maintain adequate clearance, we had to ensure that the thrust/weight ratio at liftoff was at least as high as the current RSRM's. Note in Figure 4 that the FSB has a slightly higher thrust-to-weight ratio than the current RSRM. The system level analysis showed that with that thrust performance at liftoff the FSB is able to maintain adequate clearance of the MLP posts and the only area of concern is an interference with the gaseous nitrogen purge which will necessitate a modification to that piece of hardware on the MLP.

In comparing the thrust-time history of the FSB to the current RSRM booster's, note that there is a significant increase in added capability with the FSB. That added capability could be used for a number of system performance improvements. The key one of interest for this study is how that performance can be used to enhance the overall abort capability of the Shuttle system. The abort improvements afforded by the FSB are summarized in Figure 5. All abort modes are

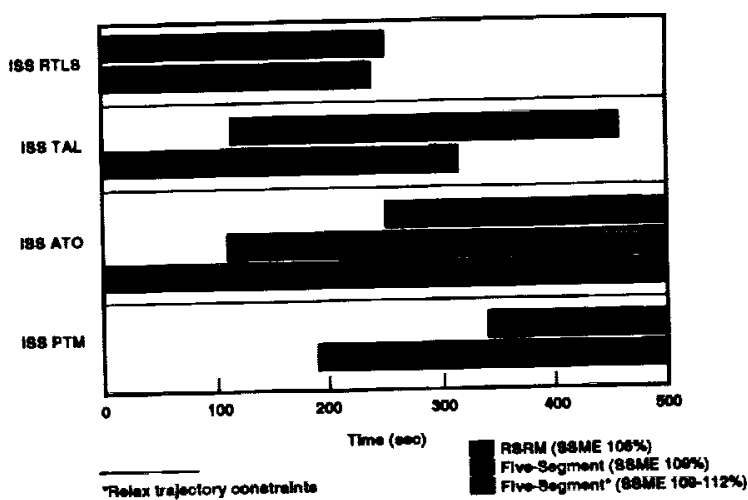

Figure 5. Abort Modes (one SSME out) Results

evaluated for trajectories going to Space Station Alpha. The aborts also assume that the abort is initiated when one Space Shuttle main engine (SSME) fails and is turned off. The time indicates the time at which the SSME would fail and the abort mode could be initiated. The top blue bar indicates when the various abort modes could be initiated for the current Shuttle system. The abort modes of primary interest are: return to launch site (RTLS), transatlantic landing (TAL), abort to orbit (ATO), and press to MECO (PTM). With the current Shuttle boosters, if an engine fails from 0 to about 250 seconds, an RTLS abort could be initiated. For the current system, the earliest that a TAL abort could be initiated is approximately 120 seconds after launch. Similarly, an ATO could be initiated at approximately 250 seconds after launch. The second bar shown in green indicates the abort performance capability associated with using the FSB as currently configured. In its current configuration, the FSB would allow a TAL abort to be initiated off the pad with a SSME throttle setting of 109 percent. An ATO abort could be initiated at approximately 110 seconds after launch with the FSB. One of the alternate considerations for future aborts was evaluating the various trajectory constraints that are applied in an abort scenario. Some key abort trajectory constraints that were considered for modification are: 
1) once an abort is initiated, fly due east as opposed to continuing toward the high inclination for a nominal SSA mission; 2) increase the angle of attack (alpha) profile to fly a more lofted trajectory once an abort is initiated (increasing the alpha profile results in a trajectory which forces the apogee altitude of the boosters higher than what the current recoverability constraint would tolerate, but in an abort mode the attrition rate associated with recovering the boosters is not an important criteria); 3) use or dump the OMS/RCS propellant for thrust during ascent. Additionally, you would offload 42,000 pounds of liquid oxygen (LOX) and modify the mixture ratio of the SSME to 5.87 to compensate for the change in the amount of LOX. When these constraints are relaxed, the current FSB would provide the ability to initiate an ATO from the pad, assuming a SSME throttle setting of between 109 and 112 percent. Initial indications are the FSB would enhance the contingency aborts and decrease the blackout zones as well increasing the east coast landing windows for various abort scenarios. But the contingency aborts were not evaluated in detail as part of the Phase A study.

The increased capability afforded by the FSB provides a significant increase in mission planning flexibility. The increased capability, as previously discussed, provides a significant improvement in abort capability by providing ATO off the pad, which would eliminate RTLS and TAL. The equivalent payload capability of the added payload capability of using the FSB would be approximately 20,000 pounds. This is in excess of the down-weight capability the orbiter can accommodate. However, the added payload capability could accommodate other Shuttle system safety upgrades such as crew escape. When balancing the overall improvement to system reliability, concepts such as crew escape would most likely provide a more significant system safety enhancement than that afforded by abort mode improvements, and as such, the added capability of the larger boosters would provide an even more significant system safety improvement by facilitating other safety upgrades. The higher performance capability could also allow a reduced SSME throttle setting for the duration of a nominal performance missions, which should improve overall system reliability. The increased capability could also enable off-nominal flight conditions where additional boost capability would be needed to compensate for degradations in other system performance attributes similar to what occurred on the Chandra mission.

As part of the Phase A study, a significant number of feasibility assessments were conducted by the various FSB team members to ensure the overall adequacy of the FSB design concept. A summary of the major feasibility assessment issues is contained in Table 1 . With the added segment, there is an increase in the length-todiameter ratio of the motor as well as an increase in the propellant bore diameter-to-throat diameter ratio, both of which contribute to increasing the Mach number in the bore of the motor during the first second of motor operation. During this period of time, the combined effects of increased mass flow and increased Mach number increase the propensity for burn rate enhancement due to erosive burning. The analytical assessment conducted as part of the Phase A study indicated this would be nearly a 40-psi increase in maximum operating pressure. Historical data shows this phenomenon to be a consistently reproducible effect, and once predicted the design could be modified to accommodate this phenomenon. As part of the Phase A study, subscale motor static test firings at high length-to-diameter ratios have been conducted to better understand this phenomenon. 
Table 1. Feasibility Assessment

\begin{tabular}{|c|c|c|}
\hline Technical Issue & Impact & Resolution \\
\hline $\begin{array}{l}\text { Propellant Erosive } \\
\text { Burning }\end{array}$ & $\begin{array}{l}\text { Potential for propellant burn rate } \\
\text { enhancement during first } 1-2 \text { sec of } \\
\text { burn time, resulting in increased } \\
\text { pressure }\end{array}$ & $\begin{array}{l}\text { Analysis shows that pressure increase is on } \\
\text { order of } 30 \mathrm{psl} \\
\text { Subscale testing being conducted to validate } \\
\text { analysis }\end{array}$ \\
\hline Nozzle Torque & $\begin{array}{l}\text { Increased flex bearing stiffness due } \\
\text { to new nozzle aggravates SRB TVC } \\
\text { capability }\end{array}$ & $\begin{array}{l}\text { Evaluation conducted and no TVC redesign } \\
\text { anticipated for nominal TVC operation }\end{array}$ \\
\hline $\begin{array}{l}\text { Booster Re-entry } \\
\text { Environments }\end{array}$ & $\begin{array}{l}\text { Increased vibroacoustic and aero- } \\
\text { heating environments aggravates } \\
\text { current SRB component and TPS } \\
\text { capability }\end{array}$ & $\begin{array}{l}\text { Analysis indicates no major redesign antici- } \\
\text { pated, will require requalification of some elec- } \\
\text { tronic components and increased TPS thick- } \\
\text { ness. May require shock isolation mounts for } \\
\text { some electronics }\end{array}$ \\
\hline $\begin{array}{l}\text { Aerodynamic Heating } \\
\text { Environments }\end{array}$ & $\begin{array}{l}\text { Increased aero and shifted shock } \\
\text { heating aggravates current TPS } \\
\text { capability }\end{array}$ & $\begin{array}{l}\text { Analysis of SRB nose cone and ET indicates no } \\
\text { major redesign anticipated, will require localized } \\
\text { TPS thickness increases on forward SRB and } \\
\text { ET components. Requires analysis for all Shut- } \\
\text { tle elements to confirm redesign is limited to } \\
\text { components already identified }\end{array}$ \\
\hline $\begin{array}{l}\text { Plume-Induced Heating } \\
\text { Environments }\end{array}$ & $\begin{array}{l}\text { Increased radiation and re- } \\
\text { circulation heating aggravates cur- } \\
\text { rent TPS capability }\end{array}$ & $\begin{array}{l}\text { Analysis of ET and single bodypoint per ele- } \\
\text { ment indicates no major redesign anticipated, } \\
\text { will require localized TPS thickness increases } \\
\text { on aft SRB and ET components. Requires } \\
\text { analysis for all Shuttle elements to confirm re- } \\
\text { design is limited to components already identi- } \\
\text { fied }\end{array}$ \\
\hline $\begin{array}{l}\text { Pre-launch Loads and } \\
\text { Excursions }\end{array}$ & $\begin{array}{l}\text { Increased weight and length en- } \\
\text { hances overturning moment which } \\
\text { aggravates current SRB aft skirt, } \\
\text { case capability, and vehicle } \\
\text { umbilicals }\end{array}$ & $\begin{array}{l}\text { Analysis indicates that case and skirt are ade- } \\
\text { quate, will require aft skirt structural testing to } \\
\text { validate analysis and use of standard weight } \\
\text { case stiffener cylinders. Requires L\&L to in- } \\
\text { clude disconnects in their facility modifications } \\
\end{array}$ \\
\hline $\begin{array}{l}\text { Ignition Over Pressure } \\
\text { and MLP Plume Im- } \\
\text { pingement } \\
\text { Environment } \\
\end{array}$ & $\begin{array}{l}\text { Increased environment aggravates } \\
\text { liftoff loads and SRB thermal curtain } \\
\text { and MLP capability }\end{array}$ & $\begin{array}{l}\text { No feasibility issues but may require some re- } \\
\text { design during development program. Changes } \\
\text { in component vibration levels TBD }\end{array}$ \\
\hline Liftoff Loads & $\begin{array}{l}\text { Increased environment driven by } \\
\text { FSB IOP, which aggravates vehicle, } \\
\text { attach, the orbiter wing and orbiter } \\
\text { components }\end{array}$ & $\begin{array}{l}\text { Assessment by ET and SRB currently in-work. } \\
\text { Request more extensive analysis to identify } \\
\text { additional orbiter impacts }\end{array}$ \\
\hline $\begin{array}{l}\text { Liftoff clearance With } \\
\text { MLP }\end{array}$ & $\begin{array}{l}\text { Increased FSB weight and nozzle } \\
\text { length required higher thrust to } \\
\text { weight to clear MLP hold-down } \\
\text { posts }\end{array}$ & $\begin{array}{l}\text { Will require system control biasing and modifi- } \\
\text { cations to } \mathrm{GN}_{2} \text { purge line only }\end{array}$ \\
\hline $\begin{array}{l}\text { FCS Liftoff and Flight } \\
\text { Stability }\end{array}$ & $\begin{array}{l}\text { Changes in stability aggravates ac- } \\
\text { ceptable flex criteria }\end{array}$ & $\begin{array}{l}\text { No major redesign anticipated, will require re- } \\
\text { tuned bending filters and software architecture } \\
\end{array}$ \\
\hline $1^{\text {st }}$ Stage Ascent Loads & $\begin{array}{l}\text { Increased high } Q \text { and max } g \text { loads } \\
\text { aggravate current ET structural ca- } \\
\text { pability and the orbiter wing and } \\
\text { fuselage loads }\end{array}$ & $\begin{array}{l}\text { Analysis shows localized ET structure thickness } \\
\text { increases required. Changes in component } \\
\text { vibration levels not expected. Orbiter impacts } \\
\text { will be addressed by updates to the flight enve- } \\
\text { lope }\end{array}$ \\
\hline Pre-separat & $\begin{array}{l}\text { Increased load aggravates current } \\
\text { SRB fwd separation bolt capability }\end{array}$ & $\begin{array}{l}\text { Redesign of separation bolt will be needed dur- } \\
\text { ing development }\end{array}$ \\
\hline
\end{tabular}


Table 1. Feasibility Assessment (cont)

\begin{tabular}{l|l|l}
\multicolumn{1}{c|}{ Technical Issue } & \multicolumn{1}{c}{ Impact } & \multicolumn{1}{c}{ Resolution } \\
\hline $\begin{array}{l}\text { Booster Separation } \\
\text { Clearance }\end{array}$ & $\begin{array}{l}\text { Changes in booster length, mass } \\
\text { properties and thrust tail-off changes } \\
\text { clearance characteristics }\end{array}$ & $\begin{array}{l}\text { Analysis shows that FSB meets 30 clearance } \\
\text { requirements }\end{array}$ \\
\hline $\begin{array}{l}\text { Booster Splashdown } \\
\text { Loads }\end{array}$ & $\begin{array}{l}\text { Increased booster inert weight in- } \\
\text { creases splashdown loads }\end{array}$ & $\begin{array}{l}\text { Redesign parachutes with larger diameter to } \\
\text { reduce descent velocity and water impact loads. } \\
\text { Use standard weight cylinders for aft segment }\end{array}$ \\
\hline KSC Facility Modification & $\begin{array}{l}\text { Major modifications to existing SSV } \\
\text { processing facilities would be occur- } \\
\text { ring during periods with flight rates } \\
\text { at 7 to 8 flight per year }\end{array}$ & $\begin{array}{l}\text { Out year manifest plan will need to be adjusted } \\
\text { to create facility "down time" to allow facility } \\
\text { modifications to occur }\end{array}$ \\
\hline VAB Quantity Distance & $\begin{array}{l}\text { FSB will increase the quantity of } \\
\text { propellant in the VAB, thereby in- } \\
\text { creasing the inhabited and interline } \\
\text { building distance }\end{array}$ & Further evaluation is required \\
\hline
\end{tabular}

With the new nozzle's larger throat and larger exit cone, the overall spring rate and torque associated with the nozzle design, aggravates the overall capability of the thrust vector actuation (TVA) system. However, the flex torque of the FSB nozzle is less than that of the current RSRM nozzle due to replacing the flex boot with a bearing protector. An analysis was conducted that indicated the current TVA system has sufficient capability to meet the system performance requirements, with the new nozzle, under nominal flight conditions where both hydraulic power units are operating on each SRB.

With the increased capability of the FSB, the trajectory after booster separation results in a higher apogee than the current boosters. This results in increased vibroacoustic and aero-heating environments, which must be accommodated during the re-entry portion of the booster recovery. The Phase $A$ analysis indicated that these increased or more severe environments can be accommodated by increasing the thermal protection system (TPS) and adding shock attenuation mounts for some of the electronic components that would be subjected to the more severe vibroacoustic environment.
In viewing Figure 1, notice that the nosetip of the FSB is 30 feet farther forward than the current booster's. This creates a different aerodynamic environment and shock wave interaction than is currently experienced. The aerodynamic changes create a more severe environment for the booster nose cone as well as some increased aeroheating on the ogive portion of the ET. Both of these areas can be accommodated by adding TPS to compensate for the more severe aero-heating environment. With the higher mass flow rate and increased burn time, the plume-induced heating environment and the recirculation environment also become more severe. Both of these effects can also be compensated by localized increases in TPS on the ET as well as the booster.

By adding a segment to the booster, the prelaunch twang loads increase because of the added mass and length. These loads can be accommodated in the booster by using standard weight stiffeners in the aft segment. The aft skirt was also evaluated for these increased loads and was found to be acceptable with a minor decrease in margin of safety over the current configuration, but still within the system specification requirements. 
Ignition over pressure (IOP) and plume environments associated with ignition increase the thermal and structural loads on the RSRB thermal curtain and MLP, both of which can be accommodated with minor design changes. The IOP also creates a higher load on the vehicle attach as well as down wing load on the orbiter, both of which need to be evaluated in more detail in future studies.

As discussed earlier, the clearance of the nozzle during liftoff with the MLP indicated there is a slight interference with the gaseous nitrogen purge line, which will require some modification. By incorporating the FSB on the Shuttle system, there is going to be a change in the basic flight control system. The Boeing Integration team evaluated the impact of the FSB on the flight control system and determined the only change that would be required would be that some of the notch filters within the guidance system would require modification, with the changes required being within the capability and flexibility of the current system.

The increased capability afforded by the FSB increases the loading during the high dynamic pressure $(Q)$ and maximum acceleration $(G)$ regimes of the ascent flight profile. These do provide increased loads to the orbiter and ET. The increased loads to the ET were evaluated and can be accommodated by localized increases in thickness to various structural elements. All of the structural element modifications can be accommodated within the existing component fabrication methodologies primarily by removing less material from the basic billet for each of the components. This results in a slight increase in inert weight but no change in the basic component design or fabrication.

The current forward attach bolt that holds the booster to the ET has a negative margin relative to the desired factor of safety in the booster perform- ance specification. The FSB provides higher loads than the current booster, which will aggravate the negative margin. As such a new separation bolt will be required if a FSB is integrated into the Shuttle system. The new separation bolt, however, would be designed to meet the desired factor of safety for the booster system and as such would slightly increase the reliability of the FSB relative to the current boosters.

The current plan is to use the same booster separation motors (BSM) that are currently flying on the existing boosters and not change them when integrated into the FSB. An analysis was conducted to determine if the existing BSMs could provide adequate clearance during separation taking into account the increased mass and changes in moment of inertia for the FSB. The separation analysis indicated the FSB does meet all of the 3-sigma clearance requirements specified for the Shuttle system.

With the increased mass of the FSB, there is a potential for increasing the splashdown loads when the booster impacts water. To facilitate the increased mass for the FSB, a larger diameter parachute was designed that would ensure the impact velocity for the FSB would be the same as the current boosters. This new parachute would be made of newer lightweight materials as well as more refined design approaches that have been developed since the original booster parachutes were designed. The new design approach has already been demonstrated with two drop tests using the current Shuttle boosters. The larger diameter parachutes with the improved material will be able to package within the current volume available in the existing frustum. Modifying structural thicknesses of load-carrying elements and changing TPS thicknesses can accommodate the total impact on the ET of the increased thermal loads and struc- 
tural loads. The added loads resulted in a total ET weight increase of approximately 650 pounds.

Incorporating the FSB into the Shuttle system will, of course, impact the launch site at KSC. By adding a fifth segment to the booster, the current rotate process surge facility (RPSF) will not have sufficient storage capacity for the added segment. As such, a third surge facility would have to be built to accommodate the additional FSB segments. With the added center segment, the assembly facilities in High Bays 1 and 3 of the vehicle assembly building (VAB) would need additional work platforms for the added segment. The MLP would require additional thermal protection material to counteract the higher mass flow rate and thrust from the FSB. As mentioned previously, a gaseous nitrogen purge line would need to be modified to facilitate the clearance of the nozzle during liftoff. With the higher mass flow rate from the FSB, there may also need to be a modification to the sound suppression system on the MLP. The extra joint will necessitate a modification to the joint heater umbilical to accommodate the extra circuit for an additional field joint heater.

Since the booster is 30 feet longer than the current RSRM, an access platform will need to be added to allow access to the forward skirt, which is now 30 feet higher than the current booster's. With the 30-foot increase in booster length, there will be an interference with the gaseous oxygen (GOX) vent arm. This will necessitate a structural modification to the GOX vent arm. This is strictly a structural modification and not any design feasibility-related issue.

The retrieval of the boosters after recovery will require a deeper dive to install the diver-operated plug into the nozzle. The motor is sufficiently longer and will now require a minisub or special diver operations because of the increased depth.
The larger throat in the nozzle will also necessitate a new diver-operated plug. All of the facilities at the retrieval hangar are adequate with minor modifications. Additional ground support equipment may be required to handle the added segment as well as increasing the thickness of the pads at the slip in order to accommodate the higher loads associated with the increased weight of the FSB.

With the FSB, there will be additional propellant in the VAB during stacking and assembly operations. This added propellant increases the quantity distance $(\mathrm{Q} / \mathrm{D})$ envelopes. These increased $Q / D$ envelopes now encompass inhabited facilities that would violate general safety requirements and would require a waiver, similar to those already in effect for the current Shuttle system, to stack two full flight sets of FSBs in the VAB. This is a concern within the safety community and needs additional evaluation. There are multiple options available to mitigate this concern, but these options need further review.

The last activity in the Phase A feasibility study was to determine the scope, cost and schedule for a development program to fully qualify a FSB. Table 3 summarizes the cost estimate generated as part of this Phase A study. The overall development cost for a FSB is $\$ 1.1 \mathrm{~B}$. This includes all of the design, test, and analysis necessary to qualify the FSB for all of the major elements involved in the qualification process. For the purposes of this evaluation it was assumed that three full-scale static test firings would be sufficient to demonstrate the major modifications to the FSB. There are also wind tunnel tests to validate loads and environments, structural tests for the new forward skirt, and structural tests for the new forward attach on the case. The $\$ 1.1 \mathrm{~B}$ also includes $\$ 150 \mathrm{M}$ to facilitate procuring the necessary hard- 
Table 3. Level I Cost Summary

\begin{tabular}{rl|r} 
& & FY2001 SM \\
\hline 0 & FSB Development Program Total & 1106.6 \\
1.0 & Concept Studies/Requirements Definition (support SRR/PDR) & 51.5 \\
2.0 & System Integration (BRSS, USA) & 70.9 \\
3.0 & Motor Modifications (Thiokol) & 141.2 \\
4.0 & Booster Element Modifications & 206.6 \\
5.0 & ET Modifications & 40.0 \\
6.0 & System Testing & 219.7 \\
7.0 & Launch Facility Modifications and Ground Operations & 71.2 \\
8.0 & Flight Hardware Fabrication (hardware to support 1 ${ }^{\text {st flight only) }}$ & 71.9 \\
9.0 & Orbiter Element Certification (BRSS/USA) & 74.1 \\
10.0 & SR\&QA & 0.3 \\
11.0 & Flight Operations (USA) & 10.5
\end{tabular}

ware and tooling to support an eight-flight rate. The total program would take approximately five and half years from authority to proceed to first flight. Like the cost estimate, this schedule takes into account the three static tests, all of the major system level tests, as well as facility modifications at $\mathrm{KSC}$.

The FSB Phase A feasibility study showed that the FSB provides a low-risk, near-term approach to significantly enhance Space Shuttle system safety and reliability at a relatively low cost. This is a key Shuttle upgrade that can improve astronaut safety and increase performance margin. Overall system safety is enhanced by the opportu- nity to eliminate RTLS and TAL by providing ATO from the pad. There is also a slight increase in the booster reliability itself. The overall capability increase afforded by the FSB also could accommodate other significant Shuttle system safety upgrades, such as the crew escape module, by providing the necessary lift capability to compensate for any inert weight increases associated with those upgrades. Also provided is a flexibility to compensate for any off-nominal flight conditions that may occur during ascent. The Phase A study indicated that a total development cost would be on the order of $\$ 1 B$ with a development program duration of approximately five years. 